Recebido em: 05/07/2016.

Aprovado em: 20/09/2016.

Atuou durante 38 anos frente ao Sistema de Gerenciamento de Rede de TELECOM. Gerente de projetos na Telecomunicações do Paraná - TELEPAR e posteriormente com a privatização dei continuidade na Brasil Telecom inicialmente como Coordenador de Sistemas de Mediação e posteriormente como Coordenador de Projetos e Sistemas pela Diretoria de Operações. Atualmente é Chefe de Serviço na Coordenação-Geral de Tecnologia da Informação no Conselho Administrativo de Defesa Econômica CADE.E-mail: dpolacchini@gmail.com.

\section{Uma análise da mudança de paradigma na gestão para os stakeholders aplicada ao Conselho Administrativo de Defesa Econômica (CADE), na implantação do projeto: CADE sem papel (Sistema Eletrônico de Informações (SEI))*}

\author{
A paradigm shift in stakeholders management \\ applied in project implementation at the \\ Administrative Council for Economic Defense \\ (CADE): CADE sem papel (Electronic Information \\ System (SEI))
}

\section{Resumo}

O presente artigo faz uma análise do impacto da sinergia na gestão de stakeholders em projetos complexos, tomando por base o projeto "CADE sem Papel" do Conselho Administrativo de Defesa Econômica (CADE), cujo objetivo principal é a implantação do processo eletrônico por meio da adoção do Sistema Eletrônico de Informação (SEI). O estudo se baseia nos fundamentos estabelecidos no Project Managment Institute (PMI) para o gerenciamento dos interessados seguindo o modelo tradicional e considera a análise da sinergia na governança do projeto com a aplicação da retroalimentação sistêmica e dinâmica (em tempo real) visando minimizar os efeitos da entropia. O estudo parte de uma análise descritiva do caso por meio de pesquisa documental e participativa, com resultados que evidenciam as integrações da metodologia do Guia do Conhecimento em Gerenciamento de Projetos (PMBOK). Os processos sinérgicos foram efetivos a ponto de possibilitar a implantação da solução em curto intervalo de tempo, gerando um processo global de mudança nas áreas fim e meio, bem como para toda a sociedade. O marco temporal dessa mudança foi o dia $1^{\circ}$ de janeiro de 2015, data a partir da qual o CADE passou a utilizar. unicamente. processos eletrônicos. Para o sucesso nas alterações dos procedimentos operacionais da autarquia, adota-se um modelo efetivo de endomarketing que capacitou os 320 servidores, incluindo os ocupantes de cargos mais elevados. O reconhecimento social pode ser expresso por meio do prêmio da Transparência Ativa alcançado por uma entrega do projeto em concurso promovido pela Controladoria-Geral da União (CGU).

Palavras-chave: Stakeholders. Sinergia. Entropia. PMBOK. Retroalimentação.

\footnotetext{
Abstract

This manuscript analyzes the impact of synergy in stakeholder management in complex projects, based on the project "CADE sem Papel", implemented at the Administrative Council for Economic Defense (CADE), whose main objective is the implementation of the electronic process by adopting Electronic Information System (SEI) platform. The study is based on the premises set forth in the Project Management Institute guide for stakeholder management, and considers synergy analysis in
} 
project governance, with the implementation of systemic and dynamic (real-time) feedback, in order to minimize entropy effects. The manuscript starts from a descriptive analysis of the case through documental and participatory research, with results that demonstrate the integration of Knowledge Guide methodology in Project Management (PMBOK). Synergistic processes were effective enough to enable solution implementation in a short time, creating an expansive change process at core and support areas and delivering a relevant impact for society. In order to guarantee the success of the project, an effective model of internal marketing was adopted, training 320 servers, including those occupying higher positions. The social recognition can be expressed through the Active Transparency award achieved by a project delivery in competition sponsored by the Comptroller General (CGU).

Keywords: Stakeholders. Sinergy. Entropy. PMBOK. Feedback.

\section{Introdução}

Considerando a necessidade de as organizações públicas prestarem serviços de qualidade, é fundamental o alinhamento das expectativas dos usuários, sociedade e demais partes interessadas para a otimização dos resultados. Uma das ferramentas para alcançar esse objetivo de melhoria é a adoção de metodologias de gerenciamento de projetos pela esfera pública.

Algumas particularidades do setor público podem ensejar que o gerenciamento de projetos esteja mais sensível às influências de interesses pontuais, tanto internos como externos, e ocasionar mudanças de escopo e cenários de incertezas no planejamento, gerando, na maioria das vezes, interrupção, atraso ou até mesmo o cancelamento de projetos.

Nessa linha, o gerenciamento das partes interessadas (stakeholders) tem sido o foco dos gerentes de projetos pelo seu alto grau de influência, pois essas partes compõem o universo de pessoas que podem tanto impactar ou serem impactadas de forma positiva ou negativa as expectativas com relação aos resultados do projeto. Essa preocupação, também, se faz presente no setor privado.

Então, o que são stakeholders? A palavra inglesa stakeholders é formada pela junção da palavra stake com a palavra holder. A palavra stake pode ter a conotação de prêmio, risco, interesse, parte. Já a palavra holder pode significar proprietário, dono. A expressão "parte interessada" é uma das possíveis traduções para a palavra stakeholder em português, sendo essa a expressão adotada no guia PMBOK, um Guia do Conhecimento em Gerenciamento de Projeto (PROJECT MANAGMENT INSTITUTE, 2013). Doravante, ao longo deste trabalho, será adotada a palavra "stakeholder" ao se fazer referência à parte interessada.

Ressalta-se que a equipe de projeto e os stakeholders são fortemente impactados em todas as ações dos projetos, seja no planejamento, na execução ou no controle. Tudo depende do grau de comprometimento, de cooperação e de coesão dos agentes. O PMBOK dedica um capítulo exclusivo ao gerenciamento dos stakeholders que participam do projeto (PMBOK, 2013).

O nível de complexidade de um projeto cresce conforme o número de variáveis ou dimensões envolvidas, sejam as pessoas, organizações ou atividades, o que ocasiona proporcionalmente maiores dificuldades em sua gestão (PMBOK, 2013).

Um projeto só será exequível e gerará os resultados desejados se houver coesão e apoio suficientemente fortes. Sem isso, qualquer projeto estará fadado ao insucesso. Por outro lado, se for bem-sucedido, algo novo deve surgir. Mudanças podem agradar ou desagradar, em maior ou menor grau, àqueles a quem afeta. Contudo, há que se ter em mente que a novidade é uma mudança que interfere no estado anterior das coisas.

Assim, a adequada gestão e a busca sistêmica pelo comprometimento dos stakeholders tendem a levar ao sucesso os projetos (BOUTILLIER, 2012).

Nesse contexto estabelece-se a seguinte problemática: qual a influência da sinergia na gestão dos stakeholders no desenvolvimento de projetos complexos?

Este artigo tem como objetivo geral analisar o impacto da sinergia entre os stakeholders no desenvolvimento de projetos por meio do Estudo de Caso do Projeto CADE sem Papel.

A consecução do objetivo se dará pelo alcance dos seguintes específicos:

- Identificar e analisar os fatores que influenciam os processos de sinergia em gerenciamento de projetos tradicionais e de alta complexidade;

- Comparar as práticas de gestão de stakeholders no modelo tradicional com as utilizadas no projeto SEI;

- Avaliar os resultados obtidos na gestão das par- 
tes interessadas durante a implantação do projeto SEI.

As falhas em projetos podem decorrer de questões de interação humana, baixo entendimento na definição do escopo, elevado número de solicitações de mudanças, patrocínio com baixo índice de poder, estimativas subdimensionadas, falhas de comunicação, entre outras. Outro ponto crucial diz respeito à sistematização do gerenciamento dos stakeholders no projeto.

$\mathrm{Na}$ ausência de um modelo genérico que possa atender a todos os projetos no que tange à questão das relações humanas, criou-se uma série de ferramentas e instrumentos para controlar a duração, os resultados e os riscos. Entretanto, essas ferramentas não medem o comprometimento ou motivação da equipe dentro do projeto.

Este estudo evidencia que a análise dessa interação é denominada sinergia, sendo esta acompanhada de leis físicas que esclarecem o momento ideal para as ações de retomada ou retroalimentação para fins de ajustes no projeto. Essas ações são originárias de entropias negativas que poderão ser representadas por essa sinergia, e atuam diretamente nas relações humanas levando em consideração os três pilares: Coesão, Colaboração e Convergência (CCC).

\section{Referencial teórico}

\subsection{O Fator Humano na gestão de stakeholders}

Segundo o PMBOK (2013), identificar os stakeholders é o processo de reconhecer as pessoas, grupos ou organizações que podem afetar ou serem afetadas por uma decisão, atividade ou resultado do projeto. Busca analisar e documentar informações relevantes relativas a seus interesses, nível de engajamento, interdependências, influência e seu possível impacto no sucesso do projeto. $\mathrm{O}$ principal objetivo desse processo é possibilitar que o gerente de projetos identifique o direcionamento apropriado para cada stakeholder ou grupo de stakeholders.

O gerenciamento dos stakeholders é composto por quatro processos:

- Identificar os stakeholders - o processo de identificar pessoas, grupos ou organizações que podem afetar ou serem afetados por uma decisão, atividade ou resultado do projeto. Analisar e documentar informações relevantes aos seus interesses, nível de engajamento, interdependências, influência e seu impacto no projeto;
- Planejar o gerenciamento dos stakeholders - o processo de desenvolver estratégias apropriadas de gerenciamento para engajar os stakeholders de maneira eficaz no decorrer de todo o ciclo do projeto com base na análise das suas necessidades, interesses e impacto potencial no sucesso do projeto;

- Gerenciar o engajamento dos stakeholders - o processo de se comunicar e trabalhar com os stakeholders para atender às suas necessidades/ expectativas, abordar as questões à medida que elas ocorrem e incentivar o engajamento apropriado dos stakeholders nas atividades do projeto em todo o ciclo de vida deste.

- Controlar o engajamento dos stakeholders - o processo de monitorar os relacionamentos dos stakeholders no projeto em geral e ajustar as estratégias e planos para o engajamento destes.

A Figura 1 ilustra uma visão geral dos processos que compõem o gerenciamento dos stakeholders.

Figura 1 - Visão geral do gerenciamento dos stakeholders.

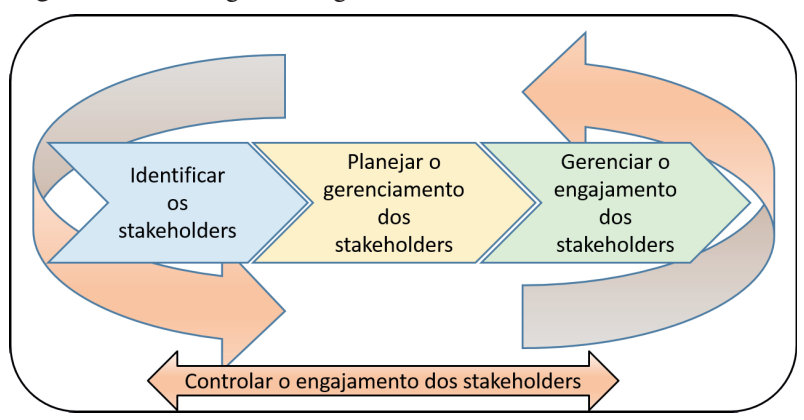

Fonte: PMBOK, 2013.

Tendo como premissa que o termo stakeholders envolve pessoas e organizações tais como clientes, patrocinadores, a organização executora e o público ativamente envolvido, suas ações podem exercer influência sobre as entradas e saídas do projeto. Os stakeholders podem estar em diversos níveis da organização e ter diferentes graus de autoridade, ou estar fora da organização executora do projeto. É fundamental para o sucesso do projeto identificá-los desde o início do planejamento e analisar seus níveis de interesse e expectativas individuais, assim como sua importância e influência. Considerando-se o tamanho, tipo e grau de complexidade, o processo de gerenciamento de stakeholders deve ser interativo e ocorrer ao longo de todo o projeto.

O gerenciamento dinâmico (em tempo real) e sistêmico dos stakeholders se justifica em função da necessidade da interação destes com as fases do projeto. As fases 
de um projeto são compostas por processos. São definidas como uma série de ações que geram produtos ou serviços (BRASIL, 2014a). Esse conjunto de processos, ilustrado na Figura 2, mostra o importante papel que os diversos agentes exercem em todos os aspectos do projeto:

a) Grupo de processos de Iniciação - define e autoriza o projeto ou uma fase do projeto;

b) Grupo de processos de planejamento - define e refina os objetivos e planeja a ação necessária para alcançar os objetivos e o escopo para os quais o projeto foi realizado;

c) Grupo de processos de execução - integra pessoas e outros recursos para realizar o plano de gerenciamento do projeto;

d) Grupo de processos de monitoramento e controle - mede e monitora regularmente o processo de identificar variações em relação ao plano de gerenciamento do projeto de forma que possam ser tomadas ações corretivas, quando necessário, para atender aos objetivos do projeto;

e) Grupo de processos de encerramento - formaliza a aceitação do produto, serviço ou resultado e conduz o projeto ou uma fase do projeto a um final ordenado.

Figura 2 - Fases do Projeto.

Nivel de

Atividade

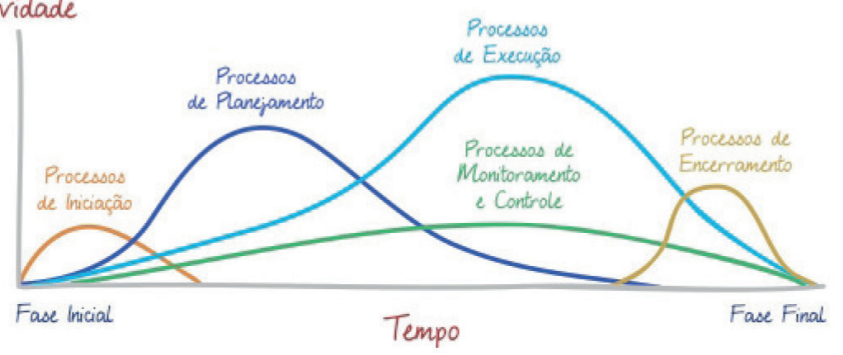

Fonte: BRASIL, 2014a.
Sternberg (1999) define stakeholder como uma pessoa que tem participação em algo que é desenvolvido por outros. Essa visão está relacionada com o fato de que algo está "em jogo, em processo de mudança”.

Existe, portanto, um risco de ganho ou de perda de algo pelo stakeholder. Com base nessa premissa, reportamos alguns conceitos segundo Sternberg (1999):

( ا) Interesse - é mais provável que as pessoas deem maior importância a um processo quando possuem interesse em seu resultado. Considera-se inclusive que o interesse não necessariamente é de ordem financeira;

(u) Complexidade da realidade - a realidade é complexa. Diversos atores estão envolvidos e podem exercer influência sobre determinado projeto. Até quem não tem interesse direto num projeto pode prejudicar o andamento em função de suas ações ou falta de ações; e

(ui) Stakeholders são detentores de direitos - esse conceito não está relacionado com a motivação financeira ou relações funcionais com o projeto.

O conceito de stakeholders existe em função da existência de direitos destes em receber algo que esteja em conformidade com a sustentabilidade das gerações futuras, ou seja, as gerações futuras merecem herdar um mundo ambientalmente preservado, por essa razão, há o entendimento de que há legitimidade da intervenção do estado em qualquer tipo de projeto (STERNBERG, 1999).

Rita Mulcahy (2013) preconiza a importância de se verificar pontos fundamentais quando do gerenciamento dos stakeholders ao longo dos projetos. O produto final os identifica nominalmente: seu cargo, papel no projeto, informações para contato, principais requisitos e expectativas, impacto e influência, atitude em relação ao projeto e as classificações em que o indivíduo se enquadra. A Figura 3 ilustra um modelo de registro de stakeholders.

Figura 3 - Modelo de Registro de Stakeholders.

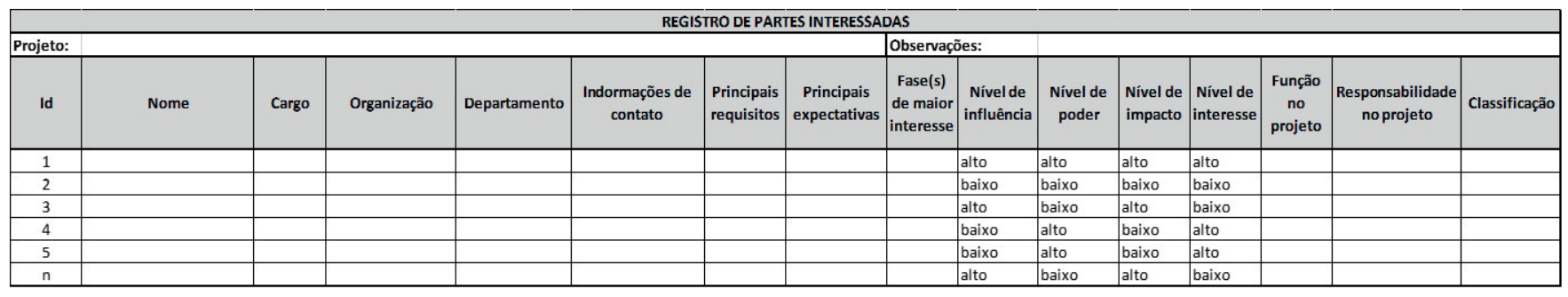

Fonte: Mulcahy, 2013. 
Nessa linha, o conceito de gerenciamento dos stakeholders torna-se problemático e complexo. Esse gerenciamento aborda processos que não são incorporados pelo gerenciamento dos stakeholders, como coletar requisitos, planejar o gerenciamento das comunicações, gerenciar as comunicações e planejar o gerenciamento dos recursos humanos, entre outros. No entanto, ele retrata o importante papel dos stakeholders em todos os aspectos do projeto.

A Figura 4 apresenta um mapa mental que destaca pontos fundamentais no gerenciamento de stakeholders.

Figura 4 - Pontos fundamentais no gerenciamento de Stakeholders.

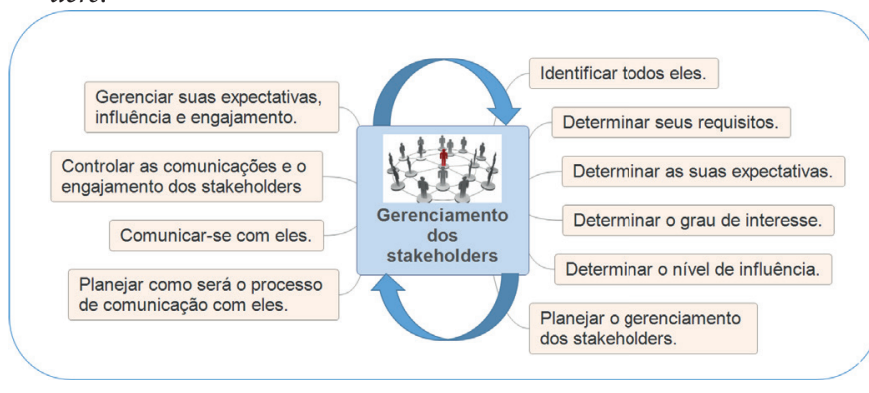

Fonte: Mulcahy, 2013 (com adaptações).

\subsection{A sinergia, a entropia e a retroalimentação em projetos complexos}

Entende-se como sinergia o efeito multiplicador das partes de um sistema que o leva a um resultado final maior do que seria a soma dos resultados parciais dessas partes, se acontecessem isoladamente (CHIAVENATO, 2004).

Quando uma equipe atua de forma sinérgica, focada no resultado comum e compartilhado, a tendência é que os resultados sejam positivos e os objetivos atingidos. Isso se deve à convergência de interesses e esforços. Dessa forma, os membros da equipe passam a fazer parte de algo maior e a compartilhar do objetivo comum, que é alcançar o bom para todos.

Evidencia-se, assim, um convívio mais agradável, pois os desafios colocados são sempre encarados como uma tarefa em equipe, de modo que as pessoas passam a se sentir parte de algo que está acima dos seus interesses individuais (soma do todo). Isso gera identidade para a equipe e tende a ser uma referência para futuros trabalhos.

Outro aspecto importante diz respeito ao fato de que todo projeto tende à entropia (caos), que é a principal causa de falhas em projetos. Entende-se como entropia a desordem ou "bagunça" que pode resultar em perdas de energia (comunicação, informação, motivação etc.) e, consequentemente, degradação do sistema (CHIAVENNATO, 2004).

Se a entropia é um processo pelo qual um sistema tende à exaustão, à desorganização, à desintegração e, por fim à morte, para sobreviver o sistema precisa abrir-se e reabastecer-se de energia e de informação para manter a sua estrutura. Sabe-se que para evitar os efeitos e impactos da entropia os processos de retroalimentação são fundamentais para manter a sinergia ao longo da realização dos projetos (ALVARES, [2016], p.).

A retroalimentação é uma parte da energia de saída de um sistema que retorna à sua entrada. Esse processo serve para comparar de alguma forma como o sistema se comporta em relação ao padrão estabelecido. Se ocorrer algum desvio ou discrepância, a retroalimentação se encarrega de alertar o sistema, viabilizando com que ajustes ou melhorias sejam realizadas.

Para que ocorra a efetiva retroalimentação, é imperativo que haja um processo sistêmico de coleta de informações ao longo de todos os processos de desenvolvimento do projeto. Um sistema retroalimentado é, necessariamente, um sistema dinâmico, ou seja, uma saída é capaz de alterar a entrada que a gerou, e, consequentemente, a si própria. Sendo assim, a interação com o ambiente no sistema aberto gera retroalimentações que podem ser positivas ou negativas, criando, dessa forma, a autorregulação regenerativa, que, por sua vez, cria novas propriedades que podem ser benéficas ou maléficas para o todo, independente das partes. (ALVARES, [2016]). A Figura 5 ilustra de forma simplificada o processo de retroalimentação.

Figura 5 - Processo de Retroalimentação.

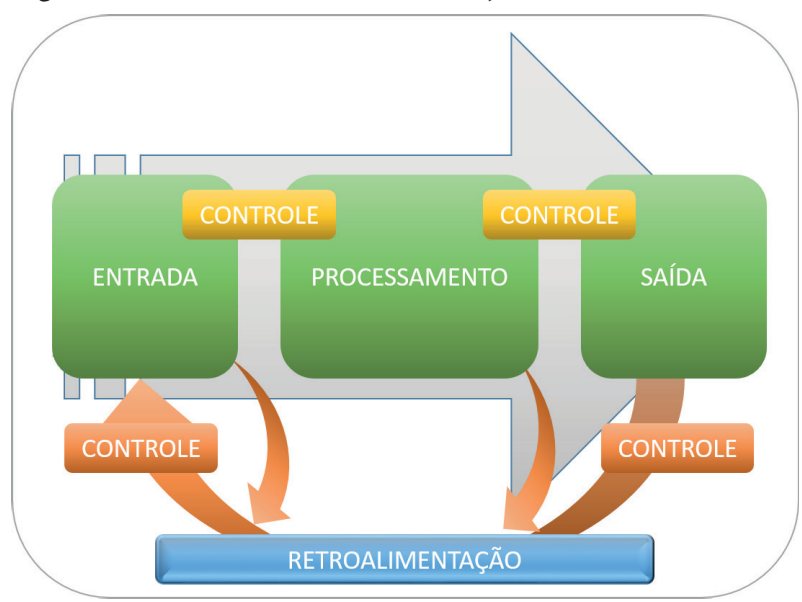

Fonte: Alvares, [2016].

Os sistemas são conjuntos de elementos dinamicamente relacionados para atingir um objetivo. Os principais conceitos relacionados com os sistemas são: 
- Entradas (inputs): o que alimenta o sistema para que ele possa operar. Constitui tudo o que o sistema recebe de seu mundo exterior (ambiente) e, genericamente, pode ser: materiais, informação e energia;

- Saídas (output): tudo o que o sistema produz é informação que serve como entrada para outros processos ou para a própria retroalimentação. Neste estudo de caso, a informação é subsídio para a redução de incerteza, pois é o conhecimento utilizado para orientar a ação e reduzir o grau de dúvida ou insegurança que cercam as decisões cotidianas;

- Processamento: é um conceito que exprime todo o trabalho (processo) que o sistema executa internamente para produzir suas saídas a partir das entradas que recebe, mas que não pode ser desvendado, pois os elementos internos são desconhecidos. Ele (o interno ao sistema) se dá a conhecer, apenas, mostrando como as manipulações e as entradas levam a tais ou quais resultados; e

- Retroalimentação: também denominado como feedback ou retro informação, constitui-se no retorno de uma parcela da energia de saída de um sistema à entrada para informar e promover mudanças necessárias.

Bertalanffy (1975), por meio da Teoria Geral dos Sistemas, demonstra o isomorfismo das várias ciências. Essa teoria é, essencialmente, totalizante: os sistemas não podem ser plenamente compreendidos apenas pela análise separada e exclusiva de cada uma de suas partes. Ela se baseia na compreensão da dependência de todos os processos e da necessidade de sua integração.

Então, o processo de retroalimentação é, na verdade, uma ação homeostática, ou seja, a busca constante do equilíbrio dinâmico, traduzindo-se em novos procedimentos de reconstrução, desconstrução e autorregulação.

\section{Método de pesquisa}

No que se refere à metodologia científica, a presente pesquisa pode ser definida como aplicada e descritiva. Segundo Vergara (2000), a pesquisa descritiva expõe as características de determinada população ou fenômeno, estabelece correlações entre variáveis e define sua natureza.
O delineamento da pesquisa é qualitativo na medida em que o estudo de caso possui como fontes os dados primários do Projeto CADE sem Papel, como relatórios, fluxos processuais e atas de reunião. A pesquisa documental é bastante utilizada em trabalhos puramente teóricos e naqueles em que o delineamento principal é o estudo de caso, pois exigem, em boa parte dos casos, a coleta de documentos para análise (MARCONI; LAKATOS, 1996).

Esta pesquisa considera a observação participativa que é uma coleta de dados para conseguir informações sob determinados aspectos da realidade. Visa identificar as inferências das relações causais tendo contato direto com a realidade, como cita Marconi e Lakatos (1996, p. 42): "[...] identificar e obter provas a respeito de objetivos sobre os quais os indivíduos não têm consciência, mas que orientam seu comportamento".

Para observar os processos sinérgicos e os fatores que influenciam o desempenho de um projeto com a adequada gestão para os stakeholders, escolheu-se o projeto CADE sem Papel, cuja principal entrega foi a implantação do processo eletrônico no órgão por meio da adoção do Sistema Eletrônico de Informações (SEI), cedido sem ônus pelo Tribunal da $4^{\mathrm{a}}$ Região da Justiça Federal (que inclui os três estados da região sul do Brasil - PR, RS, SC), a partir da celebração de Acordo de Cooperação Técnica $(\mathrm{ACT}) .^{2}$

\section{Desenvolvimento}

\subsection{Análise comparativa no modelo tradicional de gestão e o modelo adotado no projeto SEI}

A demanda que ensejou os trabalhos do Projeto CADE sem Papel originou-se em 2009, em razão da necessidade identificada pelo Conselho de tornar mais eficiente a troca de processos e informações entre os três órgãos do Sistema Brasileiro de Defesa da Concorrência (SBDC) existente na época, a saber: CADE, Secretaria de Direito Econômico (SDE/MJ) e Secretaria de Acompanhamento Econômico (Seae/MF).

Com a aprovação da Nova Lei da Concorrência (Lei n. 12.529/11, de 30 de novembro de 2011), que reestruturou o SBDC e centralizou no CADE as atividades

\footnotetext{
Minuta de Acordo de Cooperação Técnica - ACT. Disponível em: <https://softwarepublico.gov.br/social/sei/arquivos/ minuta.act.pen.sei.docx>. Acesso em: 08 maio 2016.
} 
de instrução e julgamento de processos (de condutas anticoncorrenciais e de controle de concentrações), bem como instituiu novo procedimento de notificação prévia de Atos de Concentração (AC), o plano do projeto CADE sem Papel precisou ser alterado para se ajustar ao novo arranjo institucional e às novas competências da autarquia (CADE, 2015).

Tendo como premissa que o ponto essencial para qualquer projeto é a conformação entre as necessidades dos stakeholders ou a busca pela harmonia entre as necessidades dos stakeholders e os objetivos do projeto, de nada adianta desenvolver um projeto se, ao final, o produto entregue não corresponde às expectativas e/ou necessidades destes.

Para além dos diversos agentes de um projeto, as entregas pretendidas devem focar no cliente. $\mathrm{O}$ atendimento das expectativas do cliente passa pelo conceito de valor. Valor é algo que é reconhecido quando os clientes enxergam algum benefício. (JAYASWAL; PATTON; ZULTNER, 2007).

A forma adotada na condução do projeto com foco na mudança de paradigma fez com que o CADE se tornasse referência na implantação do SEI. Esse desafio pode ser traduzido pela busca em gerenciar o projeto para os stakeholders em vez de haver preocupação em realizar o gerenciamento dos stakeholders do projeto. ${ }^{3}$ As pessoas entendem, erroneamente, que gerenciar stakeholders envolvem processos formais e burocráticos para gerir suas expectativas. Isso é mais ou menos como planejar um projeto e depois definir estratégias de maneira a evitar interferências dos stakeholders em sua execução. Na realidade estudada, a estratégia foi gerenciar o projeto para os stakeholders. Não se trata de um simples jogo de palavras, mas de uma grande mudança de paradigma (TRENTIM, 2013).

Portanto, o gerenciamento para os stakeholders deve estar fundamentado em sólida base de identificação dos benefícios desejados, definição e criação de valor e relacionamentos, em um processo de retroalimentação contínuo. A Figura 6 ilustra o gerenciamento dos stakeholders focado em valor (TRENTIM, 2013).

\footnotetext{
O SEI foi adotado por 25 instituições do Executivo Federal desde 2014, e outras 119 manifestaram interesse em aderir. O Cade tornou-se referência nessa implantação, sendo requerido para disseminar a sua metodologia de gerenciamento de projeto, o que deu ensejo a várias apresentações do projeto para os mais diversos órgãos do governo.
}

Figura 6 - Gerenciamento dos stakeholders focados em valor.

\begin{tabular}{|c|c|c|c|c|}
\hline $\begin{array}{l}\text { Listar todas as } \\
\text { partes } \\
\text { interessadas }\end{array}$ & $\begin{array}{c}\text { Avaliar a sua } \\
\text { força e } \\
\text { priorizar }\end{array}$ & $\begin{array}{c}\text { Estabelecer os } \\
\text { recursos } \\
\text { disponiveis }\end{array}$ & $\begin{array}{c}\text { Decidir a forma } \\
\text { de envolver e } \\
\text { engajar }\end{array}$ & $\begin{array}{l}\text { e } \\
\text { tar }\end{array}$ \\
\hline 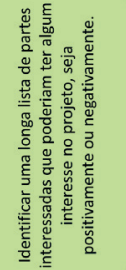 & 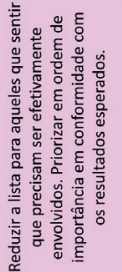 & 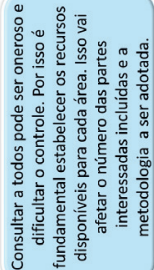 & 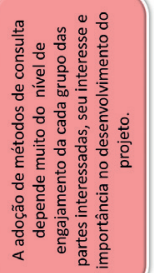 & 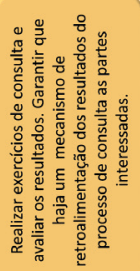 \\
\hline
\end{tabular}

Fonte: Trentim, 2013.

É fundamental identificar e listar os stakeholders desde o início da concepção do projeto. Essa lista tende a crescer ao longo do planejamento como forma de garantir que as áreas internas e externas da organização sejam contempladas. Deve-se considerar a premissa de que os stakeholders têm o poder de influenciar os destinos do projeto.

É essencial identificar, de forma clara, a relação entre o poder e o interesse no projeto em desenvolvimento como forma de minimizar o impacto sobre os resultados esperados.

A matriz da Figura 7 ilustra a identificação do grau de poder versus o nível de interesse, tendo como referência a seguinte análise:

- Grade de poder/interesse: agrupar os stakeholders nos seus níveis de autoridade ["PODER"] e nos seus níveis de preocupações ["INTERESSE”] a respeito das entregas do projeto.

- Grade de poder/influência: agrupar os stakeholders com base nos seus níveis de autoridade ["PODER"] e nos seus envolvimentos ativos [INFLUÊNCIA"] no projeto.

- Grade de influência/impacto: agrupar os stakeholders com base nos seus níveis de envolvimento ativo ["INFLUÊNCIA"] no projeto e nas suas capacidades de efetuar mudanças no plano de projeto ou na execução ["IMPACTO"].

- Grade de importância: classificar os stakeholders com base nos seus poderes ["CAPACIDADE DE IMPOR A SUA VONTADE”], urgência ["NECESSIDADE DE ATENÇÃO IMEDIATA"] e legitimidade ["SEU ENVOLVIMENTO É APROPRIADO”]. 
Figura 7 - Matriz de Relacionamento: poder versus interesse.

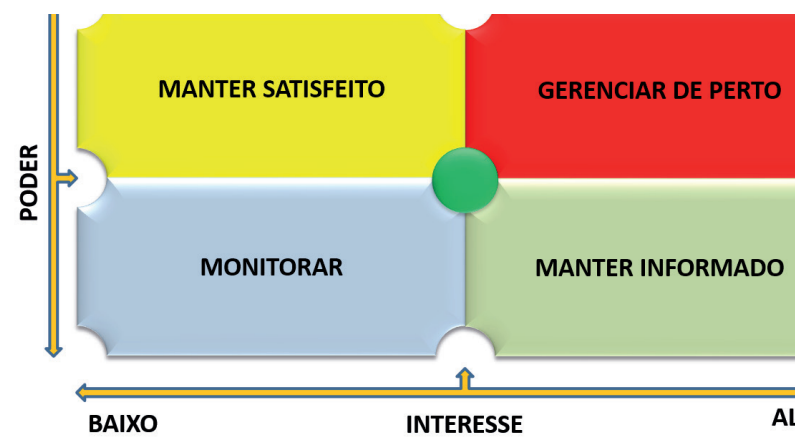

Fonte: Do Autor

Recursos humanos são ativos fundamentais no desenvolvimento de projetos. Daí a necessidade de selecioná-los de maneira tal que todas as áreas em que o projeto poderá impactar ou ser afetado tenham stakeholders participativos. Essa seleção deve ser quantitativa e qualitativa, como forma de minimizar os riscos do projeto. Devem ser identificados claramente seus papéis, habilidades necessárias, níveis de conhecimento e relacionamento. O projeto CADE sem Papel atendeu à premissa de identificação da relação "Poder versus Interesse" com a instalação dos diversos perfis demandados em um local específico para o trabalho, por meio da instalação do que foi intitulado "Sala de Guerra" do projeto.

\subsection{Aplicação da sinergia no desenvolvimento do projeto sei}

Segundo Bertalanffy (1975), uma organização retroalimentada e autogerenciada gera um sistema cujo funcionamento é dinâmico e independente, ou seja, autorregulado, no qual o todo assume as tarefas da parte que falhou. A equipe do projeto CADE sem Papel, responsável por instituir o SEI na autarquia, utilizou procedimentos que estão alinhados com essa visão e corroboram o entendimento de que o organismo é um todo maior que a soma das partes - o que chamamos de sinergia.

Para manter a sinergia, o processo de comunicação efetiva entre os agentes, é essencial. Segundo Krogh, Ichiro e Nonaka (2001), as conversas que inspiram a criação do conhecimento exigem abertura, paciência, capacidade de ouvir, experimentação de novos termos e conceitos, polidez, formação de argumentos convincentes e coragem. O gerente de projeto é como um diretor de cinema.

Este quer que cada um dos atores seja tão criativo e capaz quanto possível os estimula a desempenhar seu papel com o máximo de foco e energia. A primeira tarefa é definir o papel dos atores e para o gerente de projeto é encorajar a participação ativa nas conversas, ajudando a formar micro comunidades, onde e quando necessário. O diretor por vezes efetua cortes para assegurar a qualidade do filme e também intervém quando a integração entre atores é deficiente. Do mesmo modo, os bons gerentes de projeto interferirão nas conversas quando a qualidade dos conceitos discutidos for inaceitável, quando se abordarem ao mesmo tempo muitas ideias ou quando a compreensão entre os participantes parecer inadequada. Infelizmente gerentes de projeto, ao contrário dos diretores de cinema, não dispõe de roteiros em que se basear as intervenções (KROGH; ICHIRO; NONAKA, 2001, p. 95).

Para que se tenha, plenas, condições de manter a sinergia na gestão dos stakeholders, é fundamental atentar-se para a entropia natural que ocorre ao longo do desenvolvimento dos projetos, independentemente do porte e, para tanto, a ferramenta de retroalimentação deve ser um processo vivo e interativo, visando garantir a visão compartilhada do todo. Do ponto de vista de Senge (1990, p. 30):

Uma visão compartilhada é uma força no coração das pessoas, uma força de impressionante poder. Pode ser inspirada por uma ideia, mas quando evolui deixa de ser abstração. Torna-se palpável. Os stakeholders passam a vê-la como se existisse. Poucas forças, se é que existe uma, nas questões humanas são tão poderosas quanto uma visão compartilhada.

O desenvolvimento de projetos complexos, por si só, representa grandes desafios. Para que a equipe de projeto tenha sucesso, é crítico selecionar pessoas que tenham o desejo de solucionar problemas, para que a sinergia se mantenha viva. É fundamental que essas pessoas se sintam parte integrante da solução e tenham o sentimento claro da responsabilidade pela transformação da visão em realidade.

Senge (1990, p. 30) enfatiza que "não se pode fazer coisa alguma para impor a participação ou o comprometimento de outra pessoa. Participação e comprometimento exigem liberdade de escolha”. E sugere três regras para o desafio:

$1^{\text {a }}$ regra: Participe. Não há motivo para tentar encorajar a participação de uma outra pessoa se você não participa. Isso seria venda e não participação. Na melhor das hipóteses, produzirá uma forma superficial de acordo ou aceitação. Pior, espalhará as sementes de futuros ressentimentos.

$2^{a}$ regra: Fale sempre a verdade. Não aumente os benefícios e não esconda os problemas. Descreva a visão de forma mais simples e honesta possível.

$3^{\text {a }}$ regra: Dê aos colaboradores o direito da es- 
colha. Não é necessário convencê-los dos benefícios da visão. Quanto mais disposto você estiver ao dar o direito da escolha, mais livre ele se sentirá. Isto pode ser difícil no relacionamento com subordinados que frequentemente estão condicionados a se sentir na obrigação de segui-lo. Mesmo assim você pode ajudar, dando-lhes tempo e segurança para que possam desenvolver sua própria interpretação da visão, participação e comprometimento exigem liberdade de escolha.

Dentre as possíveis estratégias para manter viva a integração entre todos os stakeholders, o endomarketing foi adotado como campanha que contemplava a gestão de mudanças. A equipe de projeto transitava livremente pelas diversas áreas da organização buscando identificar potenciais restrições ao projeto, tendo como missão levar esclarecimentos sobre sua importância para a organização. De maneira simétrica, a equipe ouvia todas as críticas e sugestões apresentadas pelos integrantes do órgão, as analisava e avaliava a possibilidade de sua incorporação ao projeto por meio do comitê de mudanças.

Para que o SEI entrasse em produção de forma segura, estável e atendendo aos anseios do órgão e da sociedade, foi implementado um plano de capacitação dos usuários. O plano englobou a totalidade dos 320 colaboradores, em suas áreas e atividades específicas. Também foi realizada capacitação pontual para as autoridades da autarquia. A tabela 1 ilustra o plano de capacitação aplicado. Segundo Krogh, Ichiro e Nonaka (2001), promover o conhecimento estimula a inovação. Essa técnica de intervenção e moderação inspira as conversas que surgem a partir de ferramentas de comunicação. A exemplo dos "banners" distribuídos ao longo das dependências da autarquia com palavras relacionadas aos objetivos do projeto, os "broches" utilizados pelos integrantes da equipe após os treinamentos, com os dizeres "Eu SEI, pergunte-me como” garantiam seu fácil reconhecimento.

Para o processo de capacitação, foram identificados três tipos de perfis básicos:

- Alta direção: são os ocupantes de cargos de Direção e Assessoramento Superiores - DAS 4, 5 , 6 e Natureza Especial - NE. Precisam de conhecimentos básicos do sistema em suas rotinas de trabalho. Não serão operadores frequentes do sistema, pois muitas rotinas não são de suas responsabilidades, mas precisam entender procedimentos básicos do SEI e algumas de suas aplicações às dinâmicas específicas do CADE;

- Usuário padrão: todos aqueles que operam o sistema, elaboram documentos e buscam informações. É a grande maioria dos colaboradores do CADE;

- Coordenação-Geral Processual - CGP: usuários cujas rotinas serão alteradas de maneira mais contundente, exigindo maior esforço para a organização da equipe e redesenho de tarefas.

A partir dos tipos de perfis, foram caracterizados os seguintes tipos de treinamentos:

- Básico: é o treinamento padrão mínimo para todos os colaboradores. Inclui sensibilização sobre o SEI, panorama do sistema e funcionalidades básicas. Ministrado no espaço do plenário do CADE sem necessidade de suporte do computador;

- Específico: envolve sugestões de processos de trabalho para as rotinas e uso mais avançado das ferramentas do sistema. Exige a utilização de computador o que torna as turmas menores. Constitui-se de três blocos: área meio, área-fim e CGP;

- Sensibilização: reunião com todas as chefias do CADE para ressaltar a importância do uso do módulo de treinamento do sistema e da utilização de suas funcionalidades.

Com esse plano de capacitação, o CADE garantiu que todas as unidades onde estão distribuídos seus colaboradores estariam em plenas condições de enfrentar o grande desafio de uma mudança de paradigma nas suas rotinas diárias. Tratava-se de uma virada total nos seus métodos de trabalho - até 31 de dezembro de 2014 trabalhava-se com processos em papel e, a partir de 2 de janeiro de 2015 , todos os processos passaram a ser $100 \%$ digitais, tanto para a área meio como a área-fim. 
Tabela 1 - Plano de capacitação.

\begin{tabular}{|c|c|c|c|}
\hline Título & Descrição & Quem? & Objetivos de Instrução \\
\hline Módulo Básico & $\begin{array}{l}\text { Apresentação geral do SEl e regras } \\
\text { de funcionamento do CADE a partir } \\
\text { de } 2015 \text {, e apresentar os impactos } \\
\text { de implementação para a unidade } \\
\text { interna e externa (máx. } 70 \text { pessoas) }\end{array}$ & $\begin{array}{l}\text { TODOS: Servidores, estagiários, } \\
\text { apoio administrativos e secretárias } \\
\text { de todos os setores do CADE (área } \\
\text { meio e fim) }\end{array}$ & $\begin{array}{l}\text { Conhecimentos: } \\
\text { Compreender as premissas do SEl (navegação por unidade, níveis de acesso } \\
\text { Reconhecer as funcionalidades no menu do SEI } \\
\text { Identificar as principais ferramentas do sistema } \\
\text { Identificar os impactos da implantação do SEI nas rotinas internas e externas de } \\
\text { trabalho. } \\
\text { Habilidades: uso das funcionalidades do SEl (link de documentos) necessárias. } \\
\text { Atitudes: explorar } 0 \text { ambiente de treinamento }\end{array}$ \\
\hline
\end{tabular}

Principais comandos para criar e movimentar processos e documentos, relacionamento entre processos, funcionalidades de gestão interna (máx. 36 pessoas)

Módulo 1

Acesso externo e Avocação (máx. 36

$\begin{array}{ll}\text { Módulo } 2 & \begin{array}{l}\text { Acesso ex } \\ \text { pessoas) }\end{array}\end{array}$

Módulo $3 \quad \begin{aligned} & \text { Sessão d } \\ & \text { pessoas) }\end{aligned}$

Módulo 4 Botão CADE para coleta de dados para estatísticas (máx. 36 pessoas)

TODOS: Servidores, estagiários, apoio administrativos e secretárias de todos os setores do CADE (área meio e fim)

\section{Conhecimentos:}

Iniciar um processo e incluir documentos (interno e externo)

Habilidades: uso das funcionalidades do SEl (link de documentos) necessárias Atitudes: Utilizar 0 editor do SEl para elaborar documentos Propor soluçōes para as rotinas das áreas.

Tribunal e Superintendência: servidores e secretários Coordenação-Geral Processual: servidores e apoios administrativos
Conhecimentos: compreender a dinâmica de concessão de acesso externo (sistema e processo interno) e avocação de processos. Apresentar a rotina de acesso. Diferenciar Usuário Externo X Acesso Externo.

Habilidades: uso das funcionalidades do SEI (link de documentos) necessárias Atitudes: explorar 0 ambiente de treinamento.
Tribunal e Superintendência: servidores e secretários Coordenação-Geral Processual: servidores e apoios administrativos.

Servidores da SuperintendênciaGeral, Departamento de Estudos Econômicos e Procuradoria Federal

- Servidores e apoios administrativos da Coordenação-Geral Processual

Coordenação-Geral Processual: servidores e colaboradores do Arquivo e Biblioteca.
Conhecimentos: compreender a dinâmica de criação dos documentos da pauta e ata de julgamento

Habilidades: uso das funcionalidades do SEl (link de documentos) necessárias. Atitudes: explorar 0 ambiente de treinamento.
Conhecimentos: informaçoes contidas nos botões e momento de preenchimento;

Compreender como gerar relatórios usando o $\mathrm{BI}$

Habilidades: uso das funcionalidades do SEI (link de documentos) necessárias.

Atitudes: atenção a detalhes, para auditorias no sistema 


\subsection{SEI - resultados obtidos - aplicação da sinergia}

Observa-se que a sinergia existe quando duas ou mais causas produzem, agindo conjuntamente, um efeito maior do que a soma dos efeitos que produziriam quando atuando individualmente. Assim, a sinergia consiste no efeito multiplicador das partes de um sistema em alavancar seu resultado global. Enfatiza-se que a base de referência para o sucesso do projeto teve como pilares: Coesão, Colaboração e Convergência (CCC). O segredo para evitar os efeitos e impactos da entropia ao longo do desenvolvimento do projeto foi a retroalimentação aplicada de forma integrada, em tempo real, a todos os processos em andamento.

Dessa forma, o Projeto CADE sem Papel contribuiu para a atuação mais eficiente da autarquia, na medida em que otimizou as rotinas de trabalho, disponibilizou instrumentos de gestão de processos e das equipes e possibilitou a organização do conhecimento. Ademais, a eliminação de papel com a adoção do processo eletrônico promove a sustentabilidade econômica e ambiental, além de gerar redução dos custos de transação para os administrados.

Essa solução permite ao CADE concentrar seus esforços na construção da capacidade de detecção proativa de problemas concorrenciais e focar nos elementos essenciais para a consecução da política pública de defesa da concorrência no Brasil.

Vale ressaltar que a atuação mais eficiente do CADE produz efeitos em curto e em longo prazo para o ambiente econômico e sociedade como um todo, tais como: (i) reduz pressões para aumentos de preços pelo exercício de poder de mercado; (ii) favorece o investimento em pesquisa e o desenvolvimento de tecnologias; (iii) incentiva o aumento de produtividade; e (iv) cria uma atmosfera mais favorável e menos incerta ao investimento.

\subsection{Impactos na instituição e na sociedade: promo- ção da transparência ativa e/ou passiva - ino- vação}

Em 2015, a Controladoria Geral da União - CGU instituiu o $3^{\circ}$ Concurso de Boas Práticas da CGU. O concurso foi realizado em cinco etapas e distribuído em categorias: (i) Aprimoramento das Auditorias Internas; (ii) Aprimoramento dos Controles Internos; (III) Aprimoramento das Apurações Disciplinares e de Responsabilização de Entes Privados; (IV) Aprimoramento das Ativi- dades de Ouvidoria; e (V) Promoção da Transparência Ativa e/ou Passiva.

O CADE foi o vencedor da categoria Promoção da Transparência Ativa e/ou Passiva com uma das entregas do Projeto CADE sem Papel, a Pesquisa Pública de Processos Administrativos. Trata-se de módulo desenvolvido internamente que funciona acoplado ao SEI.

No sistema SEI, o acesso aos processos pelo público externo era limitado às pessoas previamente cadastradas como usuárias externas, o que possibilitava, ainda, a liberação dos processos eletrônicos para a assinatura virtual de documentos, tais como contratos e convênios. Para tanto, era necessário o credenciamento do interessado por obtenção de login e senha de acesso ao sistema.

Assim, o sistema estava apto a atender a transparência passiva, ou seja, disponibilizar informações públicas em atendimento a demandas específicas. Contudo, havia uma lacuna, ou seja, o CADE não atendia à transparência ativa nas questões referentes a Lei de Acesso à Informação (LAI) (Lei n. 12.527/2011, de 18 de novembro de 2011), que regulamenta o direito constitucional de acesso às informações públicas (BRASIL, 2011).

$\mathrm{O}$ CADE tem como preocupação a divulgação do andamento de seus processos classificados como públicos e o acompanhamento pelas partes e advogados como garantia do devido processo legal. $\mathrm{O}$ andamento dos processos deve ser uma fonte fiável de informações em tempo real, permitindo visualizar o estágio em que se encontra e sua composição, com acesso integral às peças processuais públicas.

No que diz respeito à transparência ativa, a Resolução n. 11/2014, de 24 de novembro de 2014 instituiu o SEI como sistema de processo eletrônico do CADE. Também determinou que qualquer pessoa pode ter acesso aos processos e documentos no SEI, bem como acompanhar o trâmite processual, independentemente de credenciamento prévio, ressalvadas as hipóteses legais de restrição de acesso.

A Pesquisa Pública de Processos Administrativos (disponível pelo sítio web www.cade.gov.br, com acesso pelo botão "Pesquisa Processual") eliminou a necessidade de deslocamento ao CADE para a consulta de processos públicos e mereceu elogios do público externo ante a divulgação proativa, em local de fácil acesso, no âmbito de sua competência, de informação geral de interesse coletivo por si produzida ou custodiada.

Dentro da busca pela celeridade e transparência 
na gestão pública, em 7 de outubro de 2015, foi publicado o Decreto ${ }^{\circ} 8.539$, que dispõe sobre o uso do meio eletrônico para a realização do processo administrativo no âmbito dos órgãos e das entidades da administração pública federal direta, autárquica e fundacional. A expectativa é de que até outubro de 2017 todos os processos em papel da esfera do executivo federal migrem para o meio eletrônico (BRASIL, 2015).

Atualmente, 25 órgãos entre ministérios e autarquias já implantaram o sistema e extinguiram os processos em papel. Dos 224 órgãos federais, 119 já estão envolvidos de alguma maneira com o projeto, seja em fase de análise de viabilidade ou em fase de implantação do sistema.

\section{Considerações finais}

O contexto apresentado por este estudo baseia-se, principalmente, na problemática da influência da sinergia na gestão para os stakeholders em projetos de grande magnitude e impacto nas organizações. Por meio de análise comparativa das melhores práticas de gestão de projetos na sua forma tradicional com o modelo adotado no SEI, constatou-se a mudança de paradigma desse modelo para uma forma mais dinâmica de gestão, tornando-se intuitiva e, principalmente, autogerenciável.

Em relação a essa nova perspectiva, ao modelo tradicional são adicionadas novas práticas que interferem, diretamente, na forma como a equipe se relaciona no desenvolvimento e implantação de um projeto. Por exemplo, pensar na organização como um ser vivo que atua diariamente e interage como um sistema biológico, ao fazer com que a integração entre conhecimento e sinergia seja um processo sistêmico.

Como fatores que foram identificados e estudados como influenciadores da sinergia dentro da gestão para os stakeholders neste artigo, destacam-se a Autogestão; Modelo de Gestão Compartilhada; Endomarketing; e Capacitação.

Ressaltam-se, de forma complementar, algumas regras aplicadas neste artigo como boas práticas:

Analisar segundo as melhores práticas de gerenciamento de projeto a identificação dos stakeholders;

a. Apresentar como a integração da gestão do conhecimento com retroalimentação ativa gera a sinergia;

b. Utilizar projetos de sucesso dentro da orga- nização como modelo de referência e cultura, promovendo melhorias;

c. Quebrar o paradigma com a participação ativa de toda a organização convergindo para o atingimento das metas e resultados esperados;

d. Adequar a identificação da relação de satisfação x benefícios;

e. Motivar e criar o ambiente de projeto para o processo de sinergia ser sistêmico;

f. Gerar o endomarketing da organização (vender seu produto);

g. Capacitar de forma direcionada às necessidades reais de cada público;

h. Aplicar os 3Cs - Coesão, Colaboração e Convergência;

i. Promover reconhecimento dos participantes e do próprio projeto.

Dentre os principais fatores limitantes, pode-se destacar as bibliografias disponíveis, uma vez que tratam, isoladamente, da importância da gestão dos stakeholders, sem que considerem claramente a integração ativa da gestão do conhecimento com as ferramentas e técnicas da gestão de projetos. Entretanto, para o desenvolvimento deste estudo de caso, não se considerou que essa dissociação tenha causado restrições aos seus resultados.

Como este estudo de caso não teve como foco a integração dos stakeholders com a totalidade de processos adotados no âmbito de gerenciamento de projetos, sugere-se que seja aprofundado o estudo do tema sinergia em Gerenciamento de Projetos como uma agenda futura de estudo.

\section{Referências}

ALVARES, Lilian. Teoria geral dos sistemas, [2016]. Material de aula da disciplina Planejamento e Gestão de Unidades Arquivísticas, do curso de Arquivologia da Universidade de Brasília. Disponível em: <http://lillian. alvarestech.com/Planejamento/Modulo1/Aula11TGS. pdf>. Acesso em: 06 mar. 2016.

BERTALANFFY, Ludwig Von. Teoria geral dos sistemas. São Paulo: Vozes, 1975. Disponível em: $<$ https://www.google.com.br/webhp? sourceid=chrome-instant\&ion $=1 \& \mathrm{espv}=2 \& \mathrm{ie}=\mathrm{UTF}-8 \# \mathrm{q}=\mathrm{Te}-$ oria+Geral+dos+Sistemas\%3B+BERTALANFFY\%2C+Ludwig+Von.\%3B+Ed.+Vozes\%3B197>. Acesso em: 18 mar. 2016. 
BOUTILLIER, R. A stakeholder approach to issues management. Nova York: Business Expert, 2012.

BRASIL. Conselho Administrativo de Defesa Econômica. Projeto Cade sem papel. Sitio com informações detalhadas sobre o projeto Cade sem papel. 2016. Disponível em: <http://sempapel.cade.gov.br/>. Acesso em: 23 mar. 2016.

BRASIL. Conselho Administrativo de Defesa Econômica. Resolução n. 11, de 24 de novembro de 2014b. Institui o sistema eletrônico de informações. Disponível em: <http://www.cade.gov.br/upload/Despacho\%20339\%20 -\%20Resolu\%C3\%A7\%C3\%A3o\%20n\%C2\%BA\%20 11\%20de\%202014.pdf>. Acesso em: 23 mar. 2016.

BRASIL. Decreto n. 8.539, de 8 de outubro de 2015. Dispõe sobre o uso do meio eletrônico para a realização do processo administrativo no âmbito dos órgãos e das entidades da administração pública federal direta, autárquica e fundacional. Disponível em: <http://www.planalto.gov. br/ccivil_03/_Ato2015-2018/2015/Decreto/D8539.htm>. Acesso em: 24 mar. 2016.

BRASIL. Escola Nacional de Administração Pública. Gerência de projetos: teoria e prática: módulo 1: introdução ao gerenciamento de projetos. Brasília: ENAP, 2014a.

BRASIL. Lei n. 12.527, de 18 de novembro de 2011. Regulamenta o direito constitucional de acesso às informações públicas. Disponível em: <http://www.acessoainformacao.gov.br/assuntos/conheca-seu-direito/a-lei-de-acesso-a-informacao>. Acesso em: 23 mar. 2016.
CHIAVENATO, Idalberto. Introdução à teoria geral da administração. 7. ed. São Paulo: Campus, 2004.

JAYASWAL, B. K.; PATTON, P. C.; ZULTENER, R. E. Understanding customer needs: software QFD and voice of the customer. Upper Saddle River: Prentice Hall, 2007.

KROGH, G. V.; ICHIRO, K.; NONAKA, I. Facilitando a criação do conhecimento: reinventando a empresa com o poder da inovação contínua. Rio de Janeiro: Campus, 2001.

MARCONI, M. A.; LAKATOS, E. M. Técnicas de pesquisa: planejamento e execução de pesquisas, amostragens e técnicas de pesquisas, elaboração e interpretação de dados. 3. ed. São Paulo: Atlas, 1996.

MULCAHY, Rita. Preparatório para o exame de PMP. 8. ed. Rio de Janeiro: RMC Publications, 2013.

PROJECT MANAGMENT INSTITUTE. Um guia do conhecimento em gerenciamento de projetos. 5. ed. Newton Square: PMBOK, 2013.

STERNBERG, E. The stakeholder concept: a mistaken doctrine. Leeds: Foundation for Business Responsibilities, 1999.

TRENTIM, Mário Henrique. Managing Stakeholders as Clients. Newtown Square: Project Management Institute, 2013.

VERGARA, Sylvia C. Projetos e relatórios de pesquisa em administração. 3. ed. São Paulo: Atlas, 2000. 